\title{
Power measurement for an atmospheric pressure plasma jet at different frequencies: distribution in the core plasma and the effluent ${ }^{\star}$
}

\author{
Torsten Gerlinga ${ }^{\mathrm{a}}$, Ronny Brandenburg, Christian Wilke, and Klaus-Dieter Weltmann \\ Leibniz Institute for Plasma Science and Technology (INP Greifswald), Felix-Hausdorff-Str 2, 17489 Greifswald, Germany
}

Received: 23 December 2016 / Received in final form: 27 February 2017 / Accepted: 28 March 2017

(c) The Author(s) 2017

\begin{abstract}
The characterization of electrical power distribution in an atmospheric pressure plasma jet operated at six different frequencies is investigated by measurement of input power and voltage-charge plots for the core plasma and the plasma in the effluent. The frequency change is further characterized by measuring the temperature in the effluent at different positions and input power levels. The power input into the core plasma is limited to about $1 \mathrm{~W}$ for a wide range of frequencies while the total input power and thus the power input into the effluent increases continuously with frequency.
\end{abstract}

\section{Introduction}

Cold atmospheric pressure plasma jets cover a wide range of potential applications, e.g., plasma medicine, where these devices offer a high potential for therapeutic use [1]. While the basic research on biological effects in this field is meanwhile well established, the physics of the plasma sources itself must be well understood in order to explain the treatment effects and to address safety issues $[2,3]$.

In plasma medicine, the aspect of efficacy is yet a topic for discussion, since the classification of effective agents is difficult due the variety, the individual response of the treated object, and the difficulties to measure them $[1,4]$. Especially in the case of plasma jets, the "effluent" that interacts with the surface is not identical with the "core" plasma in the ignition zone. During the ignition phase, a discharge is formed between the electrodes and afterward emitted with a high electric field in form of a bullet into the surrounding air and onto the target [5-8]. One important value for the comparison of different plasma sources is the input power [9-13].

In the present contribution, one parameter is investigated that is supposed to scale with the process efficacy at a simplified setup of an ac-driven atmospheric pressure plasma jet, similar as the kINPen. The focus is on the plasma power, which is determined for different operating frequencies. In addition, temperature measurements are used to trace an application driven parameter for the different settings. By further measuring the dissipated power

\footnotetext{
a e-mail: gerling@inp-greifswald.de

${ }^{\star}$ Contribution to the topical issue "The 15th International Symposium on High Pressure Low Temperature Plasma Chemistry (HAKONE XV)", edited by Nicolas Gherardi and Tomáš Hoder
}

inside the plasma "core" region with voltage-charge plots a localized power distribution is investigated. The relation of input power and dissipated power in the core region is discussed in order to derive the "effluent" power.

\section{Experimental setup}

The experimental setup is shown schematically in Figure 1a. A sinusoidal power supply is connected to different inductances $L$ to realize the measurements at different frequencies in the range from $80 \mathrm{kHz}$ up to $1.5 \mathrm{MHz}$. The list of the realized values is given in Table 1. Attached to the inductance is the plasma nozzle. It is the device "head" of the kINPen 09 device as described in [14]. The inner needle electrode is connected to the high voltage and a gas flow of $5 \mathrm{slm}$ argon is supplied to the nozzle. A dielectric capillary (steatite, $1.6 \mathrm{~mm}$ inner and $2.4 \mathrm{~mm}$ outer diameter) surrounds the tip electrode and shields the high voltage electrode from the grounded housing of the head. Attached to the head is a measurement capacitor $C_{\mathrm{L}}$ for the voltage-charge plots (also referred to as Lissajous figures). The input voltage $U_{1}$, the high voltage $U_{2}$ at the tip, and voltage over the capacitor $U_{3}$ are measured with voltage probes (Tektronix P6015A and P6139A). The input current $I_{1}$ is measured with current probes (Pearson 2877 or Tektronix CT 1). By adjusting the frequency the phase between $U_{1}$ and $I_{1}$ is set to zero. The temperature in the "effluent" was measured by an optical fiber probe as described in [15].

In Figure $1 \mathrm{~b}$ the equivalent circuit for the setup is presented. Due to the geometry of the plasma jet, it is necessary to separate between the "core" and the "effluent" plasma. The "core" can be interpreted as a dielectric discharge ignited between the needle tip and the grounded 
(a)

$\mathrm{I}_{1}$

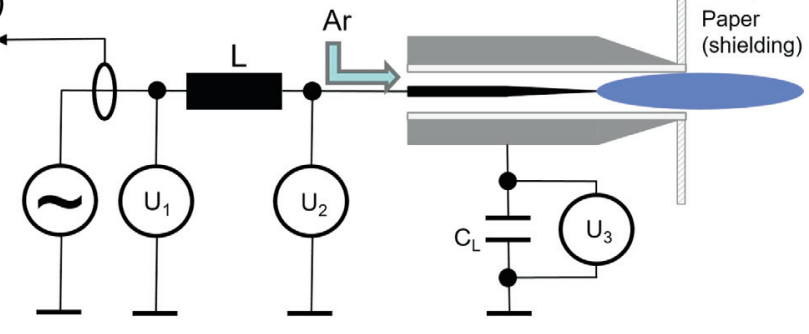

(b)

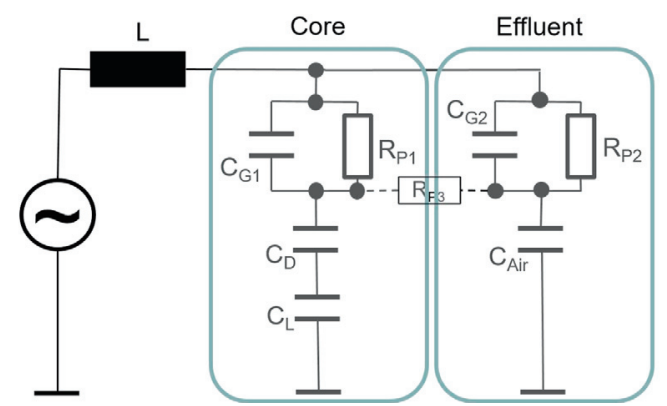

Fig. 1. (a) A scheme of the experimental setup with the electrical measurement, the sheet of paper is placed for the voltage-charge measurements; (b) simplified electrical equivalence circuit for the discharge with $C_{\mathrm{G} 1,2}$ the respective capacitance for the gap at the "core" and the "effluent", $R_{\mathrm{P} 1,2}$ the corresponding resistance in case of plasma ignition, $C_{\mathrm{D}}$ and $C_{\text {air }}$ are the capacitance of the device "head" and the surrounding air, respectively. $R_{\mathrm{P} 3}$ indicates a further complexity behind this discharge type.

Table 1. Overview of parameters in this study. The input peak voltage was varied from $40 \mathrm{~V}$ to $65 \mathrm{~V}$, the frequency was adapted for every applied voltage to be in resonance. A measurement capacitor of $C_{\mathrm{L}}=4.2 \mathrm{nF}$ was used and $C_{\mathrm{D}}=$ $3 \mathrm{pF}$ was measured. $R_{\mathrm{D}}$ is the complex impedance of $C_{\mathrm{D}}$.

\begin{tabular}{lrrrrrr}
\hline Inductance $[\mathrm{mH}]$ & 151 & 32 & 12.6 & 5.78 & 2.9 & 0.96 \\
Frequency $[\mathrm{kHz}]$ & 80 & 243 & 393 & 595 & 850 & 1500 \\
Voltage $U_{1}[\mathrm{~V}]$ & 61 & 63 & 42 & 44 & 57 & 47 \\
Current & & & & & & \\
$I_{1, \mathrm{RMS}[\mathrm{mA}]}$ & 12 & 21 & 40 & 53 & 66 & 109 \\
Voltage $U_{2}[\mathrm{kV}]$ & 3.8 & 3.4 & 3.2 & 3.1 & 3 & 3 \\
Impedance & & & & & & \\
$R_{\mathrm{D}}[\mathrm{k} \Omega]$ & 663 & 218 & 135 & 89 & 62 & 35 \\
\hline
\end{tabular}

outer electrode, which is covered by the dielectric capillary. After the core ignition a second discharge channel is ignited with the visible plasma leaving the device head and creating the "effluent" [16]. Each discharge can be represented by the parallel connection of a capacity $\left(C_{\mathrm{G} 1}\right.$, $\left.C_{\mathrm{G} 2}\right)$ and a resistance $\left(R_{\mathrm{P} 1}, R_{\mathrm{P} 2}\right)$. While for the "core" discharge the capacity is close to the measured capacity of the device head, the "effluent" is coupled via the ambient air towards any mass close by and the capacity cannot be determined. It is important to note, that the equivalent circuit is not able to account for the whole complexity of the electrical setup but gives a general insight in the plasma source.
The input power $P_{\text {in }}$ as well as the plasma power $P_{\text {plasma }}$ are determined from the respective measurements. Therefore the input power without plasma $P_{0}$ is measured for the same current value every time to estimate power losses, e.g. heat loss at the inductance [17]. The difference between input power with and without plasma results in the plasma power $P_{\text {plasma }}$ in the device "head". With the value from the voltage-charge plots the power consumption of the "head" can be separated into two parts: the "core" plasma (discharge inside the "head" onto the dielectric) and the "effluent" plasma leaving the "head". Hence the difference of the two power values should result in the power dissipated into the "effluent". The following set of equations is used $[17,18]$ :

$$
\begin{gathered}
P_{\text {in }}=\frac{1}{T} \int_{0}^{T} U_{1}(t) \times I_{1}(t) \mathrm{d} t(\text { plasma on }), \\
P_{0}=\frac{1}{T} \int_{0}^{T} U_{1}(t) \times I_{1}(t) \mathrm{d} t(\text { plasma off }), \\
P_{\text {plasma }}=P_{\text {in }}-P_{0}, \\
P_{\text {core }}=A_{\text {Liss }} \times C_{\mathrm{L}} \times f,
\end{gathered}
$$

and

$$
P_{\text {effluent }}=P_{\text {plasma }}-P_{\text {core }}
$$

\section{Results and discussion}

Increasing the plasma power $P_{\text {plasma }}$ into a plasma jet system results in an increase of the "effluent" length. The pictures of the "effluent" in Figure 2a were acquired for five different plasma power values from $1.7 \mathrm{~W}$ to $2.6 \mathrm{~W}$ according to equation (3). The emission of the "effluent" is dominated by atomic argon lines close to the nozzle, while for longer effluents the diffusion of ambient air species is increasing causing band emission of molecular nitrogen [15].

In the literature, the visible "effluent" from Figure 2 was found to be formed of positive streamers also referred to as plasma bullets or "guided streamers" $[5,16,19]$. The streamer propagation follows the electrical field lines of the device determined by the electrode geometry. Behind the streamer head a bulk of metastable argon atoms is created $[16,20,21]$. By increasing the plasma power, an increase of the electric field strength is induced and the propagating bullet travels faster and further [22]. Since the determination of the "effluent" length in Figure 2 was done visually, an error margin of $\pm 0.5 \mathrm{~mm}$ is considered. Although for longer effluents a higher loss of metastable argon atoms due to collisions with the ambient air species is observed [16,23], the linear regression in Figure 2 is in good agreement with the measured values.

As a next step, the effect of the operation frequency on the plasma power is investigated. The measured values start at the conditions for a stable discharge ignition up to the highest possible value just before parasitic discharges 
(a)

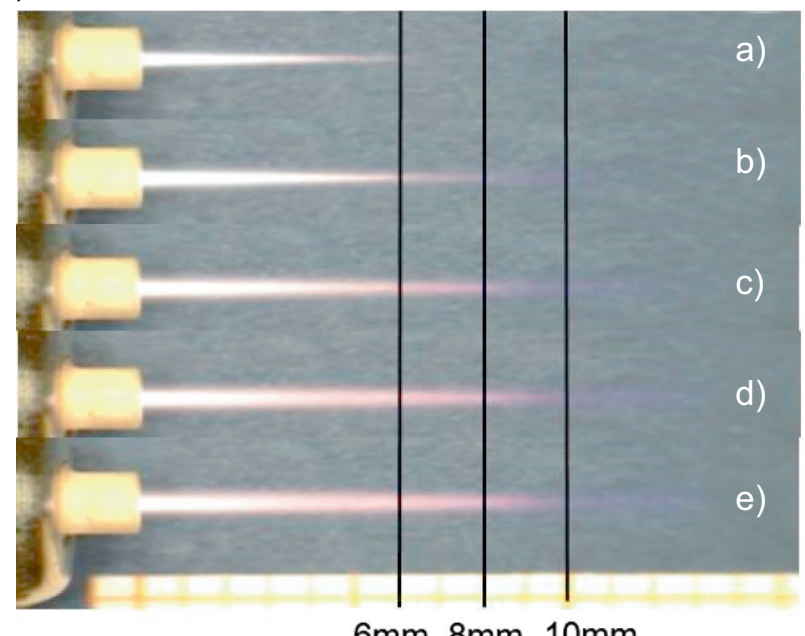

(b)

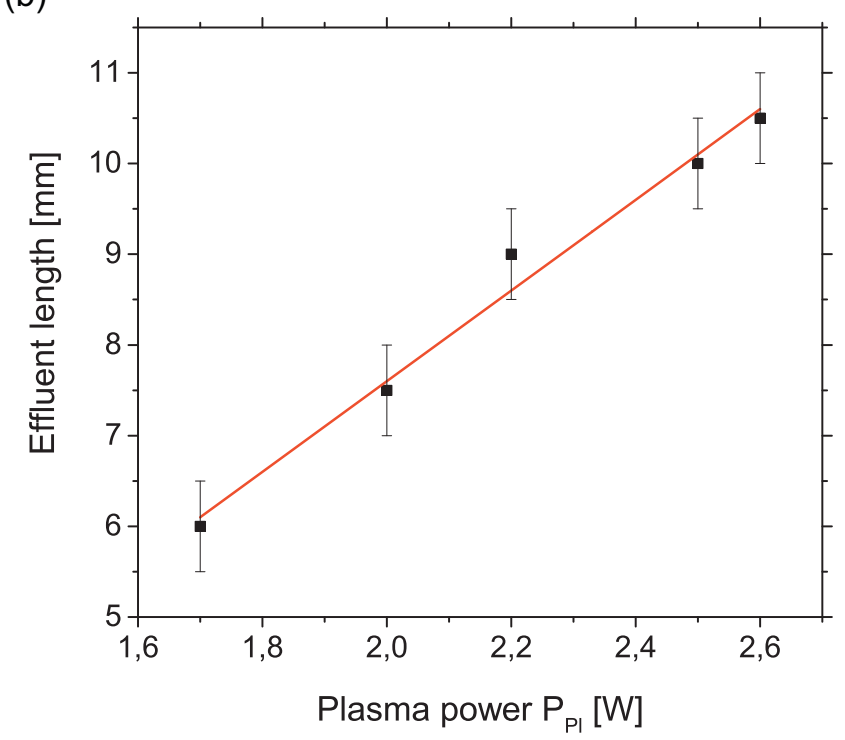

Fig. 2. (a) Pictures of the "effluent" for five power settings and a scale paper; (b) the evaluated effluent length from the pictures for the respective plasma power values with a regression curve.

could occur to the grounded device "head". The dependence of the plasma power $P_{\text {plasma }}$ on the RMS input current $I_{1}$ is shown in Figure 3 a for all six investigated operation frequencies. For higher frequencies the plasma power increases continuously. This can be explained by the impedance for the "head" $\propto 1 /\left|\omega C_{\mathrm{D}}\right|$. For the lowest frequency, the $Z$-parameter is $Z_{f=80 \mathrm{kHz}}=663 \mathrm{k} \Omega$, while for the second highest frequency $Z_{f=850 \mathrm{kHz}}=62 \mathrm{k} \Omega$. This decrease in the $Z$-parameter for the investigated frequency range results in a higher input current and hence a higher plasma power $P_{\text {plasma }}$.

A similar tendency is observed for a DBD discharge in argon with admixtures of ammonia [12], where additionally a change of the discharge regime from glow over Townsend to RF occurred. The transition in [12] was correlated with an additional increase or drop in the plasma (a)
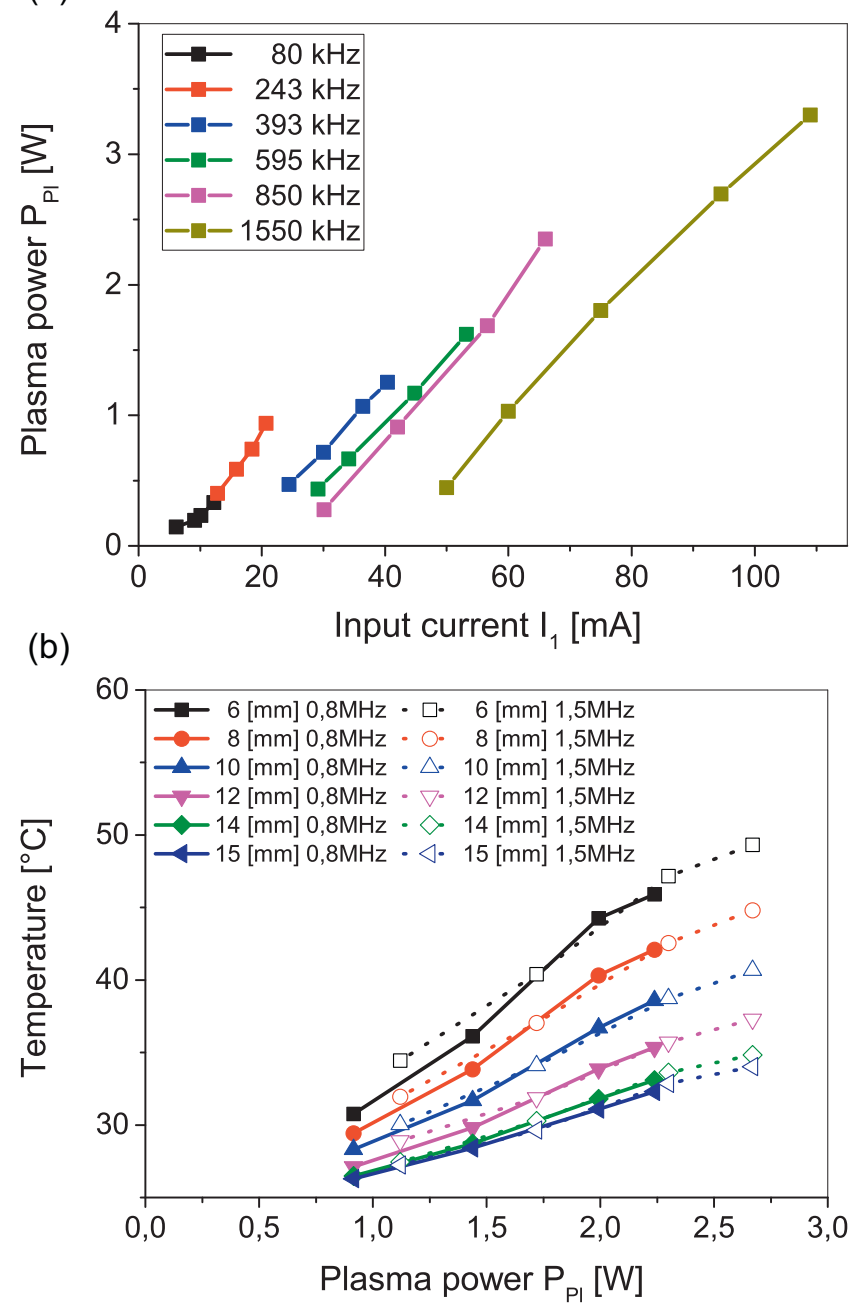

Fig. 3. (a) Plasma power as a function of input current for various frequencies; (b) measurement of temperature for different frequencies $(0.85 \mathrm{MHz}$ as straight lines and $1.5 \mathrm{MHz}$ as dotted lines) and power settings at different positions along the "effluent". Each position is colored.

power, which is not observed in the present study. Those despite not having an optical access to the "core" discharge, no such transition of discharge regimes is expected in our setup, which might be explained by less dominant Penning-ionisation processes than in [12].

The temperature in the "effluent" was measured at different positions (Fig. 3b) for different frequencies at different power values. The full lines show results for a frequency of $0.85 \mathrm{MHz}$, while the dotted lines represent a frequency of $1.5 \mathrm{MHz}$. The color of the line indicates the position, at which the temperature was measured. The full and dotted lines nearly coincide for every investigated distance. Therefore, despite the different operating frequency, the temperature scales with the plasma power. In addition, a nearly linear increase of the temperature with the plasma power is found for each distance.

The investigation of the power consumption inside the "head" was performed by voltage-charge measurements. 
In each discharge period, the surface of the dielectric capillary is charged and discharged by the plasma $[16,20]$. During the positive voltage phase a discharge towards the capillary is observed prior to the excitation of a bullet forming the effluent [16]. This correlates with a charging of the dielectric surface [8]. The discharging of the capillary occurs as a result of a conducting channel left behind by the bullet [24]. During the negative phase a corona type discharge develops and a backward bullet deposits charges onto the capillary [16,20].

Results for frequencies of $80 \mathrm{kHz}$ and $850 \mathrm{kHz}$ are shown in Figure 4. The first measurement for $80 \mathrm{kHz}$ revealed a hysteresis below a charge value of $0 \mathrm{nC}$. Already with a simple shielding by a piece of paper around the capillary orifice the hysteresis was omitted to be close to symmetric around the zero line (see for placement of paper Fig. 1). It is assumed, that the piece of paper could successfully catch the negative oxygen ions, created during the bullet propagation [25] which would otherwise be collected by the grounded housing.

Furthermore the hysteresis for a frequency of $850 \mathrm{kHz}$ shows a shift by about $-10 \mathrm{nC}$. The area under the hysteresis proved to be difficult to be evaluated. For even higher frequencies, the evaluation of the voltage-charge plots was therefore omitted. The resulting values for the dissipated power inside the "core" were calculated by using equation (4) [18]. A subtraction of the power values in the "core" from the plasma power values according to equation (5) reveal a remaining power value, which is expected to be consumed by the "effluent".

The values of the plasma power $P_{\text {plasma }}$ are presented already in Figure 3a and the power measured by the voltage-charge plot $P_{\text {core }}$ as well as the remaining power $P_{\text {effluent }}$ are presented in Figure 5 . The distinction between core and effluent is addressed by respective markers: circles for power consumption in the core and trapezoid for the consumption in the effluent. The frequencies are color coded. For a frequency of $80 \mathrm{kHz}$, the power consumed in the "core" is nearly identical to the plasma power. For frequencies from $243 \mathrm{kHz}$ up to $850 \mathrm{kHz}$, the plasma power increases steadily while the power deposition in the "core" saturates at about $1 \mathrm{~W}$. Since for higher plasma power settings, parasitic discharges around the capillary towards the grounded electrode occurred, this value seems to be the maximal power that can be consumed inside the "core". Furthermore Figure 5 shows the power consumption of the "effluent" increasing continuously for higher frequencies. By extrapolating the power limit of $1 \mathrm{~W}$ in the "core" for the highest plasma power of $1.5 \mathrm{MHz}$, a power consumption of the "effluent" of $2.3 \mathrm{~W}$ is obtained. This value is the highest value for the "effluent" within this set of measurements.

Considering the measurement for the frequency of $80 \mathrm{kHz}$, the value of the voltage-charge plot is between $20 \%$ and $30 \%$ above the plasma power. The closest explanation would be that no "effluent" was generated. Yet, the "effluent" was clearly observed. The voltage-charge plot might not consider correctly the open nature of the present system with a non-symmetric geometry and an

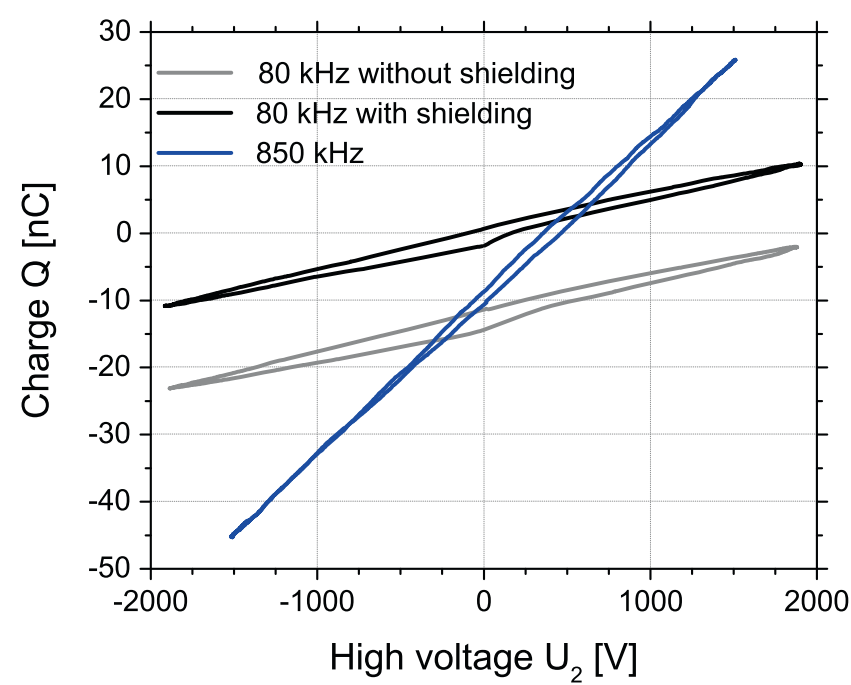

Fig. 4. Voltage-charge plot for two different frequencies. As shielding, a piece of paper was used with a hole in the middle for the capillary.

additional portion outside the "core" with the "effluent". Yet, this method is not known to be limited to symmetric barrier discharge geometries $[9,26]$. Therefore the standard deviation for up to 10 measurements is analyzed for frequencies at $240 \mathrm{kHz}$ and $850 \mathrm{kHz}$. The values are presented in Table 2. A standard deviation of up to $12 \%$ for the power in the "effluent" is found for lower frequencies, while for higher frequencies the error is reduced to $4 \%$. When exchanging the measurement capacitor $C_{\mathrm{L}}$ at a frequency of $850 \mathrm{kHz}$ for three different types of capacitors with $4.2 \mathrm{nF}$, a standard deviation of up to $34 \%$ is observed for the "effluent" power. This increase in standard deviation indicates a frequency dependence of the measurement capacitor, resulting from the quality factor of the component. For future investigations of the voltage-charge plot over a large frequency range, the selection of a capacitor with a constant quality factor over the whole measurement range should be considered.

A key observation of determining the power consumption in the "effluent" (Fig. 5) is that with the present device a higher power conversion into the "effluent" and accordingly into the production of reactive species for the plasma medical application $[1,4]$ can be achieved by increasing the operation frequency. At this point, the individual challenges of this field of application has to be considered. Therefore an increase in the plasma power will increase along others the temperature in the "effluent" (see Fig. 3b), the species densities (also of byproducts like ozone), the irradiance (also in the UV range) and the patient leakage current. In order to stay compliant with medical regulations, such a change needs to be checked regarding these and further parameters [3].

For future investigations of the power distribution the involvement of a defined substrate has to be considered. Since such a substrate would act as a third electrode, the presence would make the equivalent circuit in Figure 1 more complex. The typical procedure in this contribution 
T. Gerling et al.: Power measurement in core plasma and effluent

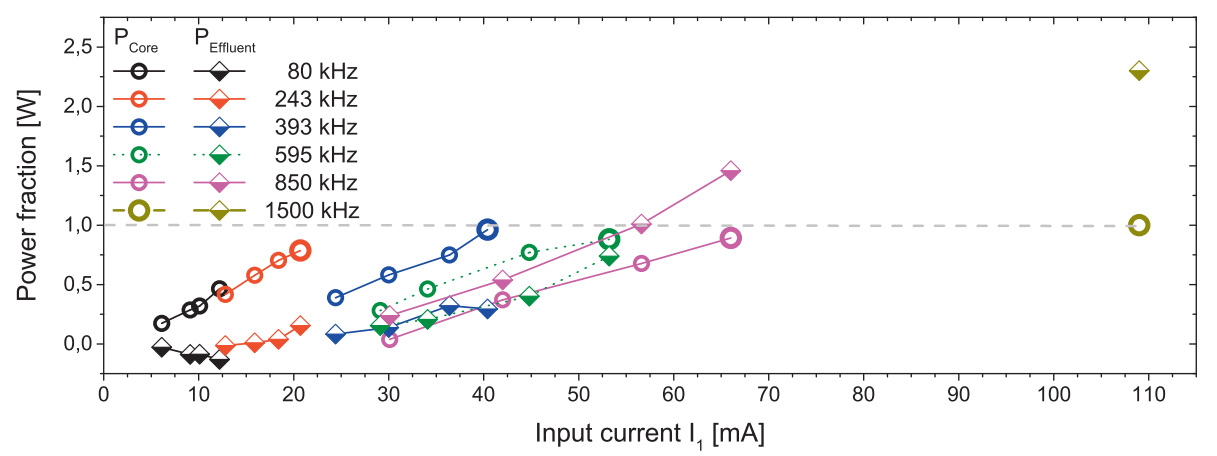

Fig. 5. Distribution of power between "core" plasma $\left(P_{\text {core }}\right.$, circle $)$ and "effluent" ( $P_{\text {effluent }}$, trapezoid $)$ for all investigated frequencies according to equation (5).

Table 2. Standard deviation for up to 10 measurements of the power distribution for frequencies at $240 \mathrm{kHz}$ and $850 \mathrm{kHz}$.

\begin{tabular}{lrcrrrrr}
\hline & $f[\mathrm{kHz}]$ & $P_{0}[\mathrm{~mW}]$ & $I_{1, \mathrm{RMS}}[\mathrm{mA}]$ & $P_{\text {in }}[\mathrm{mW}]$ & $P_{\text {plasma }}[\mathrm{mW}]$ & $P_{\text {core }}[\mathrm{mW}]$ & $P_{\text {effluent }}[\mathrm{mW}]$ \\
\hline Average value & 239.9 & 221.3 & 16.6 & 871.2 & 649.9 & 451.3 & 198.6 \\
Standard deviation & 0.2 & & 0.5 & 26.8 & 26.8 & 8.2 & 25.3 \\
Standard deviation [\%] & 0.1 & & 2.8 & 3.1 & 4.1 & 1.8 & 12.7 \\
Average value & 824.6 & 651.0 & 53.4 & 2343.6 & 1692.6 & 765.4 & 927.2 \\
Standard deviation & 0.5 & & 0.7 & 27.9 & 27.9 & 63.2 & 37.0 \\
Standard deviation [\%] & 0.1 & & 1.4 & 1.2 & 1.7 & 8.3 & 4.0 \\
\hline
\end{tabular}

is an increase in the supply voltage, effecting the input current and hence increasing the plasma power. With a surface as a third electrode, the influence on the electrical circuit starts to act only after a certain voltage is reached to bridge the additional gap (e.g., $C_{\mathrm{G} 3}$ ). And even more, the bridge occurs not in every discharge cycle but rather with a frequency of $1-5 \mathrm{kHz}$. This requires a correction of the operating frequency for each applied voltage and possibly even each voltage cycle to match the input signal phase between voltage and current. These challenges will be addressed in future investigations.

\section{Conclusion}

The power distribution in an atmospheric pressure plasma jet operated at different frequencies is investigated by means of electrical and temperature measurements. It was found, that the "effluent" length of the device scales linearly with the plasma power. For different frequencies, it could be shown that the temperature in the "effluent" matches for different positions along the "effluent". The temperature in the "effluent" scales with the plasma power.

By increasing the frequency, the plasma power into the device could be increased as a result from the reduced $Z$-parameter. The maximal power input for each frequency was limited by parasitic discharges. Further evaluation of the dissipated power inside the "core" plasma by means of voltage-charge plots revealed an offset of the hysteresis due to drifting negative ions from the "effluent" to the device nozzle. The power consumption inside the "core" could be shown to saturate at 1 W. By subtracting the power consumption from the the plasma power, a remaining power value remained that was discussed to be consumed by the "effluent", leaving the device "head". For higher frequency settings it was found that the power consumption of the "effluent" increased from $0.2 \mathrm{~W}$ at $243 \mathrm{kHz}$ up to $2.3 \mathrm{~W}$ at $1.5 \mathrm{MHz}$. This could be of great interest for the design conception of effective plasma devices in the future for multiple areas of application.

The authors are grateful to R. Kohls, N. Lembke and C. Meyer for technical assistance as well as to S. Iseni, A. Pipa and S. Reuter for fruitful discussions. Furthermore, the authors are grateful for the funds received by the German Ministry of Education and Research (BMBF, grant 13N13960) and by the Ministry of Education, Science and Culture of the State of Mecklenburg-Vorpommern (grant: AU 15 001).

\section{References}

1. T. von Woedtke, S. Reuter, K. Masur, K.D. Weltmann, Phys. Rep. 530, 291 (2013)

2. J. Winter, R. Brandenburg, K.-D. Weltmann, Plasma Sources Sci. Technol. 24, 064001 (2015)

3. M.S. Mann, R. Tiede, K. Gavenis, G. Daeschlein, R. Bussiahn, K.D. Weltmann, S. Emmert, T. von Woedtke, R. Ahmed, Clin. Plasma Med. 4, 35 (2016)

4. X. Lu, G.V. Naidis, M. Laroussi, S. Reuter, D.B. Graves, K. Ostrikov, Phys. Rep. 630, 1 (2016)

5. M. Teschke, J. Kedzierski, E.G. Finantu-Dinu, D. Korzec, J. Engemann, IEEE Trans. Plasma. Sci. 33, 310 (2005)

6. R. Wild, T. Gerling, R. Bussiahn, K.-D. Weltmann, L. Stollenwerk, J. Phys. D: Appl. Phys. 47, 042001 (2014)

7. G.B. Sretenović, I.B. Krstić, V.V. Kovačević, B.M. Obradović, M.M. Kuraica, J. Phys. D: Appl. Phys. 47, 102001 (2014) 
8. T. Gerling, R. Wild, A.V. Nastuta, C. Wilke, K.-D. Weltmann, L. Stollenwerk, Eur. Phys. J. Appl. Phys. 71, 20808 (2015)

9. U. Kogelschatz, Plasma Chem. Plasma Process. 23, 1 (2003)

10. M. Holub, Int. J. Appl. Electromagn. Mech. 39, 81 (2012)

11. P. Bruggeman, R. Brandenburg, J. Phys. D: Appl. Phys. 46, 464001 (2013)

12. R. Bazinette, R. Subileau, J. Paillol, F. Massines, Plasma Sources Sci. Technol. 23, 035008 (2014)

13. J. Golda, J. Held, B. Redeker, M. Konkowski, P. Beijer, A. Sobota, G. Kroesen, N.S.J. Braithwaite, S. Reuter, M.M. Turner, T. Gans, D. O'Connell, V.S. von der Gathen, J. Phys. D: Appl. Phys. 49, 084003 (2016)

14. S. Bekeschus, A. Schmidt, K.D. Weltmann, T. von Woedtke, Clin. Plasma Med. 14, 19 (2016)

15. K.-D. Weltmann, E. Kindel, R. Brandenburg, C. Meyer, R. Bussiahn, C. Wilke, T. von Woedtke, Contrib. Plasma Phys. 49, 631 (2009)

16. R. Bussiahn, E. Kindel, H. Lange, K.-D. Weltmann, J. Phys. D: Appl. Phys. 43, 165201 (2010)

17. S. Hofmann, A.F.H. van Gessel, T. Verreycken, P. Bruggeman, Plasma Sources Sci. Technol. 20, 065010 (2011)
18. A.V. Pipa, J. Koskulics, R. Brandenburg, T. Hoder, Rev. Sci. Instrum. 83, 115112 (2012)

19. J.-P. Boeuf, L.L. Yang, L.C. Pitchford, J. Phys. D: Appl. Phys. 46, 015201 (2013)

20. S. Reuter, J. Winter, S. Iseni, S. Peters, A. SchmidtBleker, M. Dünnbier, J. Schäfer, R. Foest, K.-D. Weltmann, Plasma Sources Sci. Technol. 21, 034015 (2012)

21. S. Reuter, A. Schmidt-Bleker, S. Iseni, J. Winter, K.D. Weltmann, IEEE Trans. Plasma. Sci. 42, 2428 (2014)

22. J.L. Walsh, P. Olszewski, J.W. Bradley, Plasma Sources Sci. Technol. 21, 03400 (2012)

23. A. Schmidt-Bleker, J. Winter, A. Bsel, S. Reuter, K.D. Weltmann, Plasma Sources Sci. Technol. 25, 015005 (2016)

24. A. Shashurin, M.N. Shneider, M. Keidar, Plasma Sources Sci. Technol. 21, 034006 (2012)

25. A. Schmidt-Bleker, S.A. Norberg, J. Winter, E. Johnsen, S. Reuter, K.D. Weltmann, M.J. Kushner, Plasma Sources Sci. Technol. 24, 035022 (2015)

26. S. Pekárek, Eur. Phys. J. D 67, 1 (2013)

Open Access This article is distributed under the terms of the Creative Commons Attribution License http:// creativecommons.org/licenses/by/4.0/ which permits unrestricted use, distribution, and reproduction in any medium, provided the original author(s) and source are credited. 